\title{
Market Power and Transferable Property Rights
}

Author(s): Robert W. Hahn

Source: The Quarterly Journal of Economics, Vol. 99, No. 4 (Nov., 1984), pp. 753-765

Published by: Oxford University Press

Stable URL: http://www.jstor.org/stable/1883124

Accessed: 04-10-2017 22:36 UTC

JSTOR is a not-for-profit service that helps scholars, researchers, and students discover, use, and build upon a wide range of content in a trusted digital archive. We use information technology and tools to increase productivity and facilitate new forms of scholarship. For more information about JSTOR, please contact support@jstor.org.

Your use of the JSTOR archive indicates your acceptance of the Terms \& Conditions of Use, available at http://about.jstor.org/terms

Oxford University Press is collaborating with JSTOR to digitize, preserve and extend access to The Quarterly Journal of Economics 


\title{
MARKET POWER AND TRANSFERABLE PROPERTY RIGHTS*
}

\author{
ROBERT W. HAHN
}

The appeal of using markets as a means of allocating scarce resources stems in large part from the assumption that a market will approximate the competitive ideal. When competition is not a foregone conclusion, the question naturally arises as to how a firm might manipulate the market to its own advantage. This paper analyzes the issue of market power in the context of markets for transferable property rights. First, a model is developed that explains how a single firm with market power might exercise its influence. This is followed by an examination of the model in the context of a particular policy problem-the control of particulate sulfates in the Los Angeles region.

\section{INTRODUCTION}

The idea of implementing a market to ration a given quantity of resources is by no means novel. Working examples include markets for taxi medallions and liquor licenses. Suggested applications for the use of a market approach abound in the economics literature, especially in the fields of air and water pollution. ${ }^{1}$ Why has the idea of setting up a market in transferable property rights received so much attention? One key reason, and the reason which motivates this paper, is that such markets have the potential to achieve a given objective in a cost-effective manner. Whether this potential is realized depends, among other things, on the design of the market and the extent to which individual firms can exert a significant influence on the market.

The purpose of this paper will be to explore how the initial distribution of property rights can lead to inefficiencies. Section II develops the basic model for the case in which one firm can influence the market. Section III considers a potential application of the model. The results of the theoretical analysis are then

*The work reported here was supported by the Environmental Quality Laboratory at Caltech and the California Air Resources Board. I would like to thank Jim Quirk, Roger Noll, Jennifer Reinganum, and Robert Dorfman for providing helpful comments. The views expressed herein, including any remaining errors, are solely the responsibility of the author.

1. Tietenberg [1980] provides a comprehensive survey of the application of marketable permits to the control of stationary source air pollution. A general list of references to potential applications in air and water pollution is provided in the study by Anderson et al. [1979]. 
compared with the conventional wisdom, and directions for future research are discussed in Section IV.

For analytical purposes, firms are divided into two categories. A firm will be said to have market power if it realizes it has an influence on price. A firm will not have market power if it acts as a price taker. The question for analysis, then, is how a single firm with market power might influence the market by affecting the price at which a commodity sells. More precisely, this essay examines how the price strategy of a firm with market power varies with changes in the initial distribution of property rights.

In the static models developed below, all transactions take place at a single price. Restricting the model in this way permits analysis of a range of inefficient outcomes. This is in contrast to the approach taken by Coase [1960] in his seminal article, who does not restrict the bargaining space and, consequently, emphasizes the range of efficient outcomes that can result, irrespective of the initial endowment of property rights.

The principal result is that the degree of inefficiency observed in the market is systematically related to the distribution of permits. For the case of one firm with market power, the results have some intuitive appeal. If a firm with market power would elect to buy permits in a competitive market (i.e., where all firms act as if they were price takers), then it follows a strategy resembling that of a monopsonist. If it would choose to sell permits in a competitive market, then the firm with market power follows a strategy resembling that of a monopolist. These results are formalized in the next section.

\section{The BAsic Model}

A critical assumption underlying the competitive model is that firms act as if they were price takers. In the model developed below, it will be assumed that all firms except one are price takers. The basic question to be answered is how (and whether) the equilibrium price and quantities will vary as a function of the initial distribution of permits among firms.

Consider the case of $m$ firms with firm 1 designated as the firm with market power. A total of $L$ permits are distributed to the firms, with the $i$ th firm receiving $Q_{i}^{0}$ permits. Firms are allowed to trade permits in a market that lasts for one period. The number of permits that the $i$ th firm has after trading will be 
denoted by $Q_{i}$. All firms except the market power firm are assumed to have downward sloping inverse demand functions for permits of the form $P_{i}\left(Q_{i}\right)$ over the region $[0, L] . P_{i}$ represents firm $i$ 's willingness to pay. All trades in the market are constrained to take place at a single equilibrium price $P$. For concreteness, we shall consider the case of a classical pollution externality. All price-taking firms attempt to minimize the sum of abatement costs and permit costs. For the case of pollution, the assumption of downward sloping demand curves is equivalent to the assumption that marginal abatement costs are increasing. Let $C_{i}\left(Q_{i}\right)$ be the abatement cost associated with emitting $Q_{i}$ units. Marginal abatement costs, $-C_{i}^{\prime}$, are assumed to be positive and increasing, which implies that $C_{i}^{\prime}<0$ and $C_{i}^{\prime \prime}>0$ for $i=2, \ldots, m$. Price takers solve the following optimization problem:

$$
\underset{Q_{i}}{\operatorname{minimize}} C_{i}\left(Q_{i}\right)+P\left(Q_{i}-Q_{i}^{0}\right) \quad(i=2, \ldots, m) .
$$

The first-order condition for an interior solution is

$$
C_{i}^{\prime}\left(Q_{i}\right)+P=0 .
$$

This merely says that price takers will adjust the quantity used $Q_{i}$ until the marginal abatement cost equals the equilibrium price $P{ }^{2}$ Equation (2) implicitly defines a demand function $Q_{i}(P)$, which is downward sloping on $[0, L]$ for $i=2, \ldots, m$. Furthermore, note that the number of permits the $i$ th price-taking firm will use is independent of its initial allocation of permits.

The analysis of the firm with market power is less straightforward. Begin by defining an abatement cost function $C_{1}\left(Q_{i}\right)$, where $C_{1}^{\prime}<0$ and $C_{1}^{\prime \prime}>0$. This says that the firm with market power faces increasing marginal abatement costs. Firm 1 has the power to pick a price that will minimze its expenditure on abatement costs and permits subject to the constraint that the market clear. Formally, the problem is to

$$
\begin{aligned}
& \underset{P}{\operatorname{minimize}} C_{1}\left(Q_{1}\right)+P\left(Q_{1}-Q_{1}^{0}\right) \\
& \text { subject to } Q_{1}=L-\sum_{i=2}^{m} Q_{i}(P) .
\end{aligned}
$$

2. The assumption of increasing marginal abatement cost implies that the firm attains a regular minimum in solving the problem. 
Substituting the constraint into the objective function and differentiating yield the following first-order condition for an interior minimum:

$$
\left(-C_{1}^{\prime}-P\right) \sum_{i=2}^{m} Q_{i}^{\prime}+\left(L-\sum_{i=2}^{m} Q_{i}(P)-Q_{1}^{0}\right)=0 .
$$

Equation (4) reveals that the only case in which the marginal cost of abatement $-C_{1}^{\prime}$ will equal the equilibrium price is when firm 1's distribution of permits just equals the amount it chooses to use. In effect, this says that the only way to achieve a costeffective solution, where marginal abatement costs are equal for all firms, is to pick an initial distribution of permits for firm 1 which coincides with the cost-minimizing solution.

This gives rise to the following result:

Proposition 1. Suppose that there is one firm with market power. If it does not receive an amount of permits equal to the number that it holds in equilibrium, then the total expenditure on abatement will exceed the cost-minimizing solution.

The key point to be gleaned from the analysis is that the distribution of permits matters, with regard not only to equity considerations but also to cost. Traditional models of such markets view problems of permit distribution as being strictly an equity issue. ${ }^{3}$ With the introduction of market power, it was shown that the distribution of permits may also impinge on efficiency considerations.

The next logical question to explore is how the market equilibrium will vary as a function of firm 1's initial distribution of permits. Doing the necessary comparative statics yields

$$
\begin{aligned}
\left.\frac{\partial P}{\partial Q_{1}^{0}}\right|_{L=\text { constant }}=\left(\left(-C_{1}^{\prime}-P\right)\right. & \sum_{i=2}^{m} Q_{i}^{\prime \prime} \\
& \left.+\sum_{i=2}^{m} Q_{i}^{2} C_{i}^{\prime \prime}-2 \sum_{i=2}^{m} Q_{i}^{\prime}\right)^{-1} .
\end{aligned}
$$

3. The analysis by Montgomery [1972] is one such example. In this analysis firms are assumed to be price takers. For the case of one pollutant, one market, and a linear relationship between source emissions and environmental quality, Montgomery finds that the distribution of permits will have no effect on achieving the target in a cost-effective manner. 
The expression for the denominator is the second-order condition for the cost minimization and will be positive if the second-order sufficiency condition for a minimum obtains. For example, in the case of linear demand curves (i.e., $Q_{i}^{\prime \prime}=0$ ), the expression will be positive. Thus, for the case when a regular interior minimum exists, a transfer of permits from any of the price takers to the firm with market power will result in an increase in the equilibrium price. An immediate corollary to this result is that the number of permits that the firm with market power uses will increase as its initial allocation of permits is increased. Formally, the problem is to show $\left(\partial Q_{1} / \partial Q_{1}^{0}\right)>0$. By the chain rule,

$$
\frac{\partial Q_{1}}{\partial Q_{1}^{0}}=\frac{\partial Q_{1}}{\partial P} \frac{\partial P}{\partial Q_{1}^{0}} .
$$

It suffices to show that $\left(\partial Q_{1} / \partial P\right)$ is positive. By direct substitution for $Q_{i}$,

$$
\frac{\partial Q_{1}}{\partial P}=\frac{\partial\left(L-\sum_{i=2}^{m} Q_{i}(P)\right)}{\partial P} .
$$

The expression on the right-hand side of (7) equals $-\sum_{i=2}^{m} Q_{i}^{\prime}(P)$, which is positive, because demand curves are presumed to be negatively sloped.

One question that arises in this model is whether there is any systematic relationship between the distribution of permits to the firm with market power and the degree of inefficiency. If inefficiency is measured by the extent to which abatement costs exceed the minimum required to reach a stated target, then it is possible to show the following result:

Proposition 2. Let $Q_{1}^{*}$ denote the distribution of permits for the case when permit distribution equals permit use for the firm with market power. Then inefficiency increases both as $Q_{1}^{0}$ increases above $Q_{1}^{*}$ and as $Q_{1}^{0}$ decreases below $Q_{1}^{*}$.

The proposition is verified by determining how total cost $T C$ varies as a function of $Q_{1}^{0}$.

The efficient solution is derived from the following minimization:

$$
\underset{Q_{1}, \ldots, Q_{m}}{\operatorname{minimime}} T C=C_{1}\left(Q_{1}\right)+\sum_{i=2}^{m} C_{i}\left(Q_{i}\right)
$$


subject to

$$
Q_{1}+\sum_{i=2}^{m} Q_{i}=L
$$

First-order conditions imply that

$$
-C_{i}^{\prime}\left(Q_{i}\right)=P_{i}\left(Q_{i}\right)=P \quad(i=2, \ldots, m) .
$$

Differentiation of total cost with respect to $Q_{1}^{0}$ yields

$$
\begin{aligned}
\frac{\partial T C}{\partial Q_{1}^{0}} & =C_{1}^{\prime} \frac{\partial Q_{1}}{\partial Q_{1}^{0}}+\sum_{i=2}^{m} C_{i}^{\prime} \frac{\partial Q_{i}}{\partial Q_{1}^{0}} \\
& =C_{1}^{\prime} \sum_{i=2}^{m} \frac{\partial Q_{i}}{\partial Q_{1}^{0}}+\sum_{i=2}^{m} C_{i}^{\prime} \frac{\partial Q_{i}}{\partial Q_{1}^{0}} \\
& =\sum_{i=2}^{m}\left(C_{i}^{\prime}-C_{1}^{\prime}\right) \frac{\partial Q_{i}}{\partial Q_{1}^{0}} .
\end{aligned}
$$

The above expression can be simplified by noting that

$$
\frac{\partial \boldsymbol{Q}_{i}}{\partial \boldsymbol{Q}_{1}^{0}}=-\frac{\partial P}{\partial \boldsymbol{Q}_{1}^{0}} / C_{i}^{\prime \prime} .
$$

Equation (11) is obtained by differentiating (9) with respect to $Q_{1}^{0}$. Substituting equation (11) into (10) yields

$$
\begin{aligned}
\frac{\partial T C}{\partial Q_{1}^{0}} & =-\frac{\partial P}{\partial Q_{1}^{0}} \sum_{i=2}^{m} \frac{\left(C_{i}^{\prime}-C_{1}^{\prime}\right)}{C_{1}^{\prime \prime}} \\
& =-\frac{\partial P}{\partial Q_{1}^{0}} \sum_{i=2}^{m} \frac{\left(-P-C_{1}^{\prime}\right)}{C_{i}^{\prime \prime}} \\
& =\frac{\partial P}{\partial Q_{1}^{0}}\left(P+C_{1}^{\prime}\right) \sum_{i=2}^{m} \frac{1}{C_{i}^{\prime \prime}}
\end{aligned}
$$

Equation (12) implies that

$$
\frac{\partial T C}{\partial Q_{1}^{0}}>(<) 0 \quad \text { as }\left(P+C_{1}^{\prime}\right)>(<) 0 .
$$

Combining (13) with equation (4) yields the result that total cost achieves a minimum at $Q_{1}^{*}$ and will increase as the permit distribution deviates from $Q_{1}^{*}$ in either direction. 


\section{A Potential Application}

In order to apply the basic model described in the previous section, it is necessary to develop an operational test for identifying a firm with market power. How this might be done is beyond the scope of this paper. In the application discussed below, the firm holding the largest share of permits under a competitive market simulation is designated as the market power firm.

To demonstrate how the basic model can be applied, the problem of controlling particulate sulfates in the Los Angeles region was selected. This problem was chosen because it appeared to be a likely candidate for a transferable property rights scheme, and because the problem of market power could conceivably arise. Market simulations based on the assumption that firms are price takers indicate that the largest emitter of sulfur oxides, an electric utility, could account for as much as half of the total emissions, and an even higher proportion of emissions for which abatement technologies are known-i.e., controllable emissions. ${ }^{4}$

The extent of market power will in general, vary with the level of allowable emissions, the shape of the marginal abatement cost schedule for the market power firm, and the marginal abatement costs faced by all other firms. For this particular example, a permit will be defined as the right to emit one ton of sulfur oxides emissions per day for one day. Based on this definition, Figure I shows the marginal costs of abatement for the firm designated as the market power firm. ${ }^{5}$ Two curves are drawn in Figure I, a discrete step function (based on the data in Hahn [1981b]), and a continuous approximation that has the following functional form:

$$
-C_{1}^{\prime}=88,300 Q_{1}^{-0.87} .
$$

Actually, for the case of the market power firm, a continuous approximation is probably more reasonable because the abatement strategy under consideration is the desulfurization of fuel oil or the purchase of lower sulfur residual fuel oil.

A similar graph for all other firms is shown in Figure II, which illustrates the derived demand for permits at any given

4. A more detailed discussion of the market power question can be found in Hahn [1981a], and Hahn and Noll [1982].

5 . Further assumptions underlying the development of these data, such as the availability of natural gas, are discussed in Hahn [1981a]. 


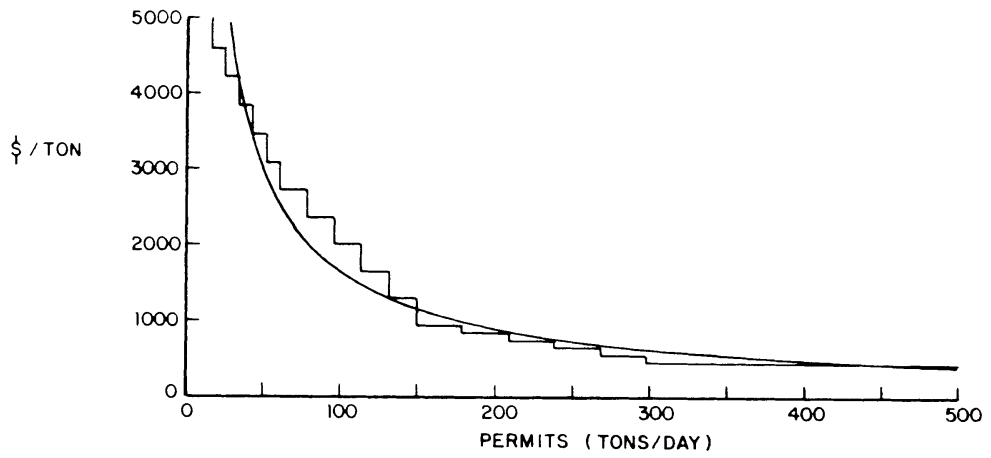

Figure I

Marginal Abatement Costs for Market Power Firm

price. The continuous approximation to the discrete case takes the following form:

$$
\sum_{i=2}^{m} Q_{i}(P)=73+\frac{154,000}{P} .
$$

The demand curve is based on some discrete technologies such as scrubbers as well as some continuous abatement strategies such as the one mentioned above. The continuous approximation will be used for purposes of illustration. Note that the particular form used in (15) implies that emissions by others will be at least 73 tons per day for all positive permit prices.

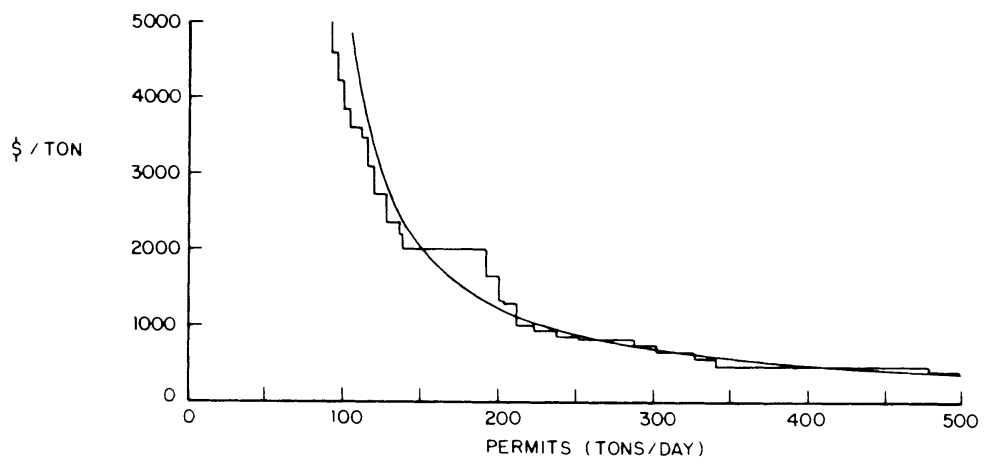

FIGURE II

Derived Demand for Permits by All Other Firms 


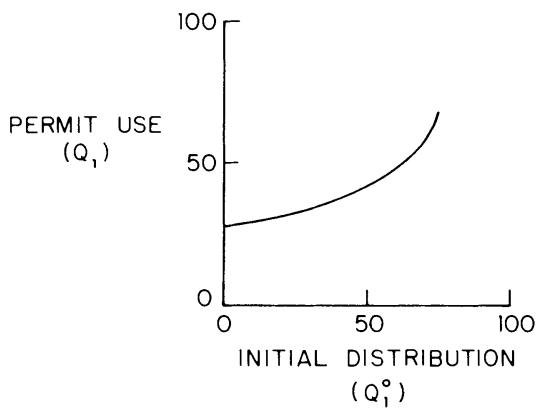

Figure III

Permit Use versus Permit Distribution-Market Power

To compute how the initial distribution of permits affects prices, quantities, and overall abatement, it is first necessary to select a value for the total number of permits. In this example the parameter $L$ was set equal to 149 tons/day, an amount which will ensure that both state and federal standards related to sulfur oxides emissions and particulate sulfates will be met. Having chosen a value for $L$, we find it possible to examine how permit use varies with initial distribution by substituting equations (14) and (15) into equation (4) and solving. The graphical solution to the problem is shown in Figure III. Note that $Q_{1}$ increases as a function of $Q_{1}^{0}$ until a corner solution is approached. This point corresponds to a permit distribution where all other firms receive an amount of permits that just equals their uncontrollable emissions. If all other firms receive an amount of permits that falls short of their uncontrollable emissions, then the relationship between $Q_{1}$ and $Q_{1}^{0}$ is not unique. In this latter case, the market power firm can reap infinite rewards by exploiting the perfectly inelastic part of the demand curve. ${ }^{6}$

Prices vary widely as a function of the initial distribution of permits. The monopsony price is approximately $\$ 3,200 /$ ton, while the competitive price, associated with $Q_{1}^{0}=36$, is about $\$ 3,900 /$ ton. ${ }^{7}$ When all other firms receive permits corresponding to their uncontrollable emissions, the price of a permit jumps to approximately $\$ 21,000 /$ ton. The monopoly price, i.e., when $Q_{1}^{0}=L$, is not well defined both in theory and in practice: in theory, because

6. In practice, such rewards would be limited by the decision of other firms to shut down operations.

7. All prices and costs are given in 1977 dollars. 


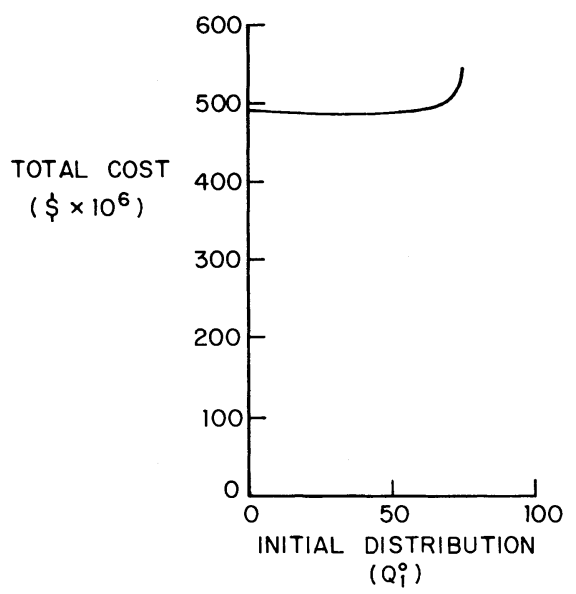

FIGURE IV

Total Annual Abatement Cost versus Initial Distribution

(15) is a hyperbola with an asymptote; and in practice, because of insufficient information on the value of firms and possible technologies that might be available for controlling so-called uncontrollable emissions.

Given permit use as a function of the initial distribution of permits, it is then possible to estimate the total annual costs of abatement by integrating equations (14) and (15). The relationship between total annual abatement expenditures and the initial distribution of permits is shown in Figure IV. Note that abatement expenditures remain relatively constant (in the neighborhood of 490 million dollars annually) until the market power firm is able to exert some monopoly power when it receives permits in excess of 60 tons per day.

The relative importance of monopolistic and monopsonistic behavior may be quite sensitive to parameter changes. In this case, monopsonistic behavior does not appear to present a problem. The reason is that in the range of the competitive equilibrium for emissions limits around this stringent standard, the supply of permits from other firms to the largest source is very sensitive to price changes. This undermines the opportunity of the firm with market power to take advantage of its high market share. As the emissions ceiling is relaxed, inefficiencies resulting from monopsonistic behavior tend to increase.

If the primary objective in setting up a market is to minimize 
total abatement costs, Figure IV indicates that the policymaker should try to avoid a situation where the firm with market power can act as a monopolist. However, because of the uncertainty associated with the cost data, it makes sense to try to minimize the likelihood that a firm or group of firms will be able to induce a price-quantity equilibrium which departs from the competitive result in either direction. Alternatives for dealing with this issue are discussed in Hahn and Noll [1982]. The theory developed in this paper indicates that the expected excess demand of each firm may be a critical variable over which the policymaker can exercise control.

\section{CONCLUSIONS}

This paper has explored the issue of market power in the context of markets in transferable property rights. The simple model developed in Section II reveals two essential points. First, just because a firm may have a large share of the permits, this does not necessarily mean it can influence the outcome in the permit market. Second, if a firm does have market power in the permit market, its effect on price (assuming that there is one firm with market power) varies with its excess demand for permits. That is to say, once the potential for market power has been ascertained, it is a flow-excess demand of the firm with market power-which determines the equilibrium.

The importance of the flow has immediate implications for market design. In particular, with full knowledge of demand functions, a central authority could effectively pick the quantity of permits it wanted the market power firm to use through a suitable initial allocation. The limits to the discretion of the authority would be dictated by two extreme cases: pure monopsony in which all permits are distributed to the price takers, and pure monopoly in which all permits are distributed to the firm with market power.

Of course, the more realistic situation is one in which the authority has, at most, only a crude estimate of the demand functions. In this case, the basic model can be applied to assess the possibilities for exerting market influence. The sensitivity of the results could be checked by varying the demand functions and the initial distribution of permits. This would allow the policymaker to determine whether the type of market influence considered here is likely to pose a problem in a given application.

The formal analysis in Sections II and III indicates the range 
of potential outcomes that might arise when firms can exert rather specific types of influence in markets which ration a fixed supply of intermediate or final goods. There are clearly other strategies that large firms might pursue, particularly when the market is just getting under way. For example, it is quite likely that the total number of permits issued and the pattern of distribution could be affected by the behavior of such firms. In the case of pollution rights, some firms might refuse to play the game if they do not care for the new set of rules. Such actions are difficult to model explicitly, which is why the focus here has been on the potential for gain within a well-defined set of rules. Even within this setting, further research is warranted.

One avenue for further research would be to extend the basic model to the case where two or more firms have market power. Hahn [1981a] has examined this issue for the case of two firms with market power. The result on cost minimization and permit distribution (Proposition 1) was shown to generalize. A second potentially fruitful area of research would be to extend the model to more than one period along the lines of Stokey [1981], who considers a durable goods monopolist. Finally, it might be useful to test the theory of the basic model in a small-group experimental setting and determine when, and under what types of institutions, it is supported.

The key result obtained here, that it is the pattern of excess demands that ultimately determines the extent to which any firm can influence the market, does not appear to be widely recognized. One reason is that many people feel that manipulation of such markets will not be a problem. For example, Tietenberg, in surveying the literature on air rights markets, expresses the view that "the anticompetitive effects of a TDP (transferable discharge permit) system are not likely to be very important in general" [1980, p. 414]. For several applications such as the one considered by DeLucia [1974] and the one considered by Hahn [1981a], the assumption that the market will approximate the competitive solution would appear to depend critically on how the institutions are designed. Because there is a very real possibility that several markets in transferable property rights could be subject to different kinds of systematic manipulation, there is a need to explore further the ramifications of such problems in theory and applications. 


\section{REFERENCES}

Anderson, R. S., Jr., R. O. Reid, E. P. Seskin, et al., "An Analysis of Alternative Policies for Attaining and Maintaining a Short Term $\mathrm{NO}_{2}$ Standard," A report to the Council on Environmental Quality prepared by MATHTECH, Inc., Princeton, New Jersey, 1979.

Coase, R. H., "The Problem of Social Cost," Journal of Law and Economics, III (1960), $1-44$.

DeLucia, R. J., An Evaluation of Marketable Effluent Permit Systems, U.S. Environmental Protection Agency, EPA-600/5-74-030, Washington, D.C., 1974.

Hahn, R. W., "An Assessment of the Viability of Marketable Permits," Ph.D. thesis, California Institute of Technology, Pasadena, California, 1981a. "Data Base and Programming Methodology for Marketable Permits Study," Open File Report No. 80-8, Environmental Quality Laboratory, California Institute of Technology, Pasadena, California, 1981b.

- , and R. G. Noll, "Designing a Market for Tradable Emissions Permits," in Reform of Environmental Regulation, W. A. Magat, ed. (Cambridge, MA: Ballinger, 1982).

Montgomery, D. W., "Markets in Licenses and Efficient Pollution Control Programs," Journal of Economic Theory (1972), 395-418.

Stokey, N. L., "Rational Expectations and Durable Goods Pricing," Bell Journal of Economics (1981), 112-128.

Tietenberg, T. H., "Transferable Discharge Permits and the Control of Stationary Source Air Pollution: A Survey and Synthesis," Land Economics, LVI (1980), $391-416$. 